\title{
Alveolar soft-part sarcoma (ASPS) resembles a mesenchymal stromal progenitor: Evidence from meta-analysis of transcriptomic data
}

\author{
Luke H Stockwin ${ }^{\text {Corresp. } 1}$ \\ ${ }^{1}$ Unaffiliated, Frederick, Maryland \\ Corresponding Author: Luke H Stockwin \\ Email address: luke.stockwin@gmail.com
}

Alveolar soft-part sarcoma (ASPS) is an extremely rare malignancy characterized by the unbalanced translocation $\operatorname{der}(17) t(X ; 17)(p 11 ; q 25)$. This translocation generates a fusion protein, ASPL-TFE3, that drives pathogenesis through aberrant transcriptional activity. Although considerable progress has been made in identifying ASPS therapeutic vulnerabilities (e.g., MET inhibitors), basic research efforts are hampered by the lack of appropriate in vitro reagents with which to study the disease. In this report, previously unmined microarray data for the ASPS cell line, ASPS-1, was analyzed relative to the $\mathrm{NCI}$ sarcoma cell line panel. These data were combined with meta-analysis of pre-existing ASPS patient microarray and RNA-seq data to derive a platform-independent ASPS transcriptome. Results demonstrated that ASPS-1, in the context of the $\mathrm{NCl}$ sarcoma cell panel, had some similarities to normal mesenchymal cells and connective tissue sarcomas. The cell line was characterized by high relative expression of transcripts such as CRYAB, MT1G, GCSAML, and SV2B. Notably, ASPS-1 lacked mRNA expression of myogenesisrelated factors MYF5, MYF6, MYOD1, MYOG, PAX3, and PAX7. Furthermore, ASPS-1 had a predicted mRNA surfaceome resembling an undifferentiated mesenchymal stromal cell through expression of GPNMB, CD9 (TSPAN29), CD26 (DPP4), CD49C (ITGA3), CD54 (ICAM1), CD63 (TSPAN30), CD68 (SCARD1), CD130 (IL6ST), CD146 (MCAM), CD147 (BSG), CD151 (SFA-1), CD166 (ALCAM), CD222 (IGF2R), CD230 (PRP), CD236 (GPC), CD243 $(A B C B 1)$, and $C D 325(C D H N)$. Subsequent re-analysis of ASPS patient data generated a consensus expression profile with considerable overlap between studies. In common with ASPS-1, elevated expression was noted for CTSK, DPP4, GPNMB, INHBE, LOXL4, PSG9, SLC20A1, STS, SULT1C2, SV2B, and UPP1. Transcripts over-expressed only in ASPS patient samples included $A B C B 5, C Y P 17 A 1, H I F 1 A, M D K, P 4 H B, P R L$, and PSAP. These observations are consistent with that expected for a mesenchymal progenitor cell with adipogenic, osteogenic, or chondrogenic potential. In summary, the consensus data generated in this study highlight the unique and highly conserved nature of the ASPS transcriptome.
Peér) reviewing PDF (2020:04:47425:1:1:NEW 20 May 2020) 
Although the ability of the ASPL-TFE3 fusion to perturb mRNA expression must be acknowledged, the prevailing ASPS transcriptome resembles that of a mesenchymal stromal progenitor. 
4

Alveolar soft-part sarcoma (ASPS) resembles a mesenchymal stromal progenitor: evidence from meta-analysis of transcriptomic data

Luke H Stockwin ${ }^{1}$

${ }^{1}$ Unaffiliated

Corresponding Author:

Luke Stockwin ${ }^{1}$

1021 N. Market St., Frederick, Maryland, 21701, United States.

Email address: luke.stockwin@gmail.com

\section{Abstract}

Alveolar soft-part sarcoma (ASPS) is an extremely rare malignancy characterized by the unbalanced translocation $\operatorname{der}(17) \mathrm{t}(\mathrm{X} ; 17)(\mathrm{p} 11 ; \mathrm{q} 25)$. This translocation generates a fusion protein, ASPL-TFE3, that drives pathogenesis through aberrant transcriptional activity. Although considerable progress has been made in identifying ASPS therapeutic vulnerabilities (e.g., MET inhibitors), basic research efforts are hampered by the lack of appropriate in vitro reagents with which to study the disease. In this report, previously unmined exon array data for the ASPS cell line, ASPS-1, was analyzed relative to the NCI sarcoma cell line panel. These data were combined with meta-analysis of pre-existing ASPS patient microarray and RNA-seq data to derive a platform-independent ASPS transcriptome. Results demonstrated that ASPS-1, in the context of the NCI sarcoma cell panel, had some similarities to normal mesenchymal cells and connective tissue sarcomas. The cell line was characterized by high relative expression of transcripts such as $C R Y A B, M T 1 G, G C S A M L$, and $S V 2 B$. Notably, ASPS-1 lacked mRNA expression of myogenesis-related factors MYF5, MYF6, MYOD1, MYOG, PAX3, and PAX7. Furthermore, ASPS-1 had a predicted mRNA surfaceome resembling an undifferentiated mesenchymal stromal cell through expression of GPNMB, CD9 (TSPAN29), CD26 (DPP4), CD49C (ITGA3), CD54 (ICAM1), CD63 (TSPAN30), CD68 (SCARD1), CD130 (IL6ST), CD146 (MCAM), CD147 (BSG), CD151 (SFA-1), CD166 (ALCAM), CD222 (IGF2R), CD230 (PRP), $C D 236(G P C), C D 243(A B C B 1)$, and $C D 325(C D H N)$. Subsequent re-analysis of ASPS patient data generated a consensus expression profile with considerable overlap between studies. In common with ASPS-1, elevated expression was noted for CTSK, DPP4, GPNMB, INHBE, LOXL4, PSG9, SLC20A1, STS, SULT1C2, SV2B, and UPP1. Transcripts over-expressed only in ASPS patient samples included $A B C B 5, C Y P 17 A 1, H I F 1 A, M D K, P 4 H B, P R L$, and PSAP. These observations are consistent with that expected for a mesenchymal progenitor cell with adipogenic, osteogenic, or chondrogenic potential. In summary, the consensus data generated in this study highlight the unique and highly conserved nature of the ASPS transcriptome. Although the ability of the ASPL-TFE3 fusion to perturb mRNA expression must be acknowledged, the prevailing ASPS transcriptome resembles that of a mesenchymal stromal progenitor. 
47

48

49

50

51

52

53

54

55

56

57

58

59

60

61

62

63

64

65

66

67

68

69

70

71

72

73

74

75

76

77

78

79

80

81

82

83

84

85

86

87

88

89

90

91

Introduction

Alveolar Soft-Part Sarcoma (ASPS) is an extremely rare soft tissue sarcoma of adolescents and young adults (Christopherson et al. 1952; Paoluzzi \& Maki 2019). ASPS usually manifests as a soft, painless, slow-growing mass and although disease follows an indolent course, it has the potential to metastasize to several sites (Portera et al. 2001). ASPS is characterized by an unbalanced translocation $\mathrm{t}(\mathrm{X} ; 17)(\mathrm{p} 11 ; \mathrm{q} 25)$ that fuses the ASPSCR1 and TFE3 genes, generating a fusion protein that drives pathogenesis (Ladanyi et al. 2001). Evidence suggests that the fusion protein accumulates in the nucleus and directs transcriptional activity (Argani et al. 2003; Betschinger et al. 2013; Hirobe et al. 2013). For example, ASPL-TFE3 binds and activates MET transcription, resulting in an overall enhancement in kinase activity in the presence of hepatocyte growth factor (Tsuda et al. 2007). As a consequence, some clinical benefit is being achieved with kinase inhibitors targeting MET (Paoluzzi \& Maki 2019; Schoffski et al. 2018).

Despite this progress, the origin of disease is still the subject of intense speculation (Folpe \& Deyrup 2006). A longstanding hypothesis posits that ASPS has a myogenous origin (Fisher \& Reidbord 1971; Folpe \& Deyrup 2006; Mukai et al. 1983). However, ASPS tumors do not appear to express markers of muscle cell differentiation such as the myogenic nuclear regulatory proteins MyoD1 and myogenin (Gomez et al. 1999; Hoshino et al. 2009; Tallini et al. 1994; Wang et al. 1996). Several transcriptomic studies have also been published that speculate on the origin of disease (Goodwin et al. 2014; Selvarajah et al. 2014; Stockwin et al. 2009; Tanaka et al. 2017). In 2009 we undertook one of the first microarray studies of ASPS and identified expression of several muscle-restricted transcripts (ITGB1BP3/MIBP, MYF5, MYF6, and TRIM63). However, these data were generated using universal RNA as a reference, which may have biased towards skeletal muscle expressed transcripts (Stockwin et al. 2009). Selvarajah et $a l$, showed that the transcription factor PAX6 was upregulated in primary ASPS, suggesting a "tentative neural line of differentiation for ASPS" (Selvarajah et al. 2014). Goodwin et al., generated microarray data from a mouse model of ASPS and also human patient samples. These authors speculated that "some mesenchymal progenitor, possibly pericyte/endothelial in character, provides one potential cell of origin" (Goodwin et al. 2014). Similarly, Tanaka et al. were able to model ASPS through ectopic expression of ASPL-TFE3 in murine embryonic, but not adult, mesenchymal cells (Tanaka et al. 2017). These observations underscore the current lack of clarity with respect to ASPS ontogeny and lend support to the suggestion that ASPS cells represent a "scrambled" phenotype where the ASPL-TFE3 fusion impairs differentiation (Folpe \& Deyrup 2006; Naka et al. 2013).

In 2011, a multi-year study culminated in the development of an ASPS cell line designated ASPS-1 (Kenney et al. 2011). This reagent provided the first opportunity to study ASPS gene expression without interference from contaminating cell types. Microarray data was subsequently generated for ASPS-1 as part of the NCI sarcoma cell line panel (Teicher et al. 2015). In the current study, ASPS-1 data was mined relative to the entire NCI sarcoma cell line panel. These efforts were combined with re-analysis of microarray and RNA-seq studies focusing on ASPS patient samples (Goodwin et al. 2014; Kummar et al. 2013; Stockwin et al. 2009). In this regard, we aimed to unify current publicly available transcriptomic data into a consensus profile that can be used as a basis for exploring disease ontogeny and therapeutic 
92 vulnerabilities. Results obtained in this study show that, at the mRNA level, ASPS resembles a

93 mesenchymal stromal progenitor.

94

95

*Throughout this report the abbreviation MSC is used interchangeably for "mesenchymal stromal cells" and "mesenchymal stem cell", although the former is preferred.

97

98

Materials and Methods

99

100

101

This study utilized six datasets downloaded from the gene expression omnibus (https://www.ncbi.nlm.nih.gov/geo/). GSE68591 comprises exon expression data (Affymetrix

102 Human Exon 1.0 v2 ST platform) for the NCI sarcoma cell line panel (includes data from ASPS1, 67 sarcoma lines, and five normal tissues) (Teicher et al. 2015). GSE13433 comprises mRNA expression data for seven ASPS patient tumors analyzed using the Affymetrix U133 plus 2.0 platform (Stockwin et al. 2009). For the analyses of data from GSE13433, additional U133 plus 2.0 control arrays were obtained from GSE17070 (normal skeletal muscle) and GSE118370 (normal lung). GSE32569 comprises a set of U133 plus 2.0 microarrays generated from six patients pre- and post- treatment with Cediranib (Kummar et al. 2013). Lastly, GSE54729 comprises RNA-seq data (HiSeq 2000) from five ASPS patients and three skeletal muscle controls. The overall study design is illustrated in Figure 1. For experiments involving Affymetrix human Exon 1.0 ST and U133 plus 2.0 arrays differentially expressed genes were identified using the Transcriptome Analysis Console (TAC 4.0, ThermoFisher Scientific) using standard algorithm and comparison settings (RMA normalization, $\mathrm{P}<0.05$, FDR $<0.05$, fold change $+/-2$ ). The TAC was also used to generate hierarchical clusters using the automated workflow. For RNA-seq data, differential expression values relative to skeletal muscle were determined using the GSE54729_10408R.txt spreadsheet that accompanies the submission. In detail, normalized FKPM values were averaged for the 5 human ASPS samples and the 3 normal human skeletal muscles samples; fold changes were then calculated from these values. In terms of utilities; the GTEX portal (https:/www.gtexportal.org/) multi gene query option (https://gtexportal.org/home/multiGeneQueryPage) was used to inform tissue of origin from the top 50 differentially expressed ASPS-1 transcripts. Similarly, the GTEX Top 50 expressed genes search function (https://gtexportal.org/home/topExpressedGenePage) was used to identify genes expressed selectively in skeletal muscle. The Protein Atlas (https://www.proteinatlas.org/) was used to investigate both mRNA and protein expression in normal and cancerous samples for specific transcripts. The in silico surfaceome (http://wlab.ethz.ch/surfaceome/) (Bausch-Fluck et al. 2018) was used to predict the hierarchy of cell surface protein expression for ASPS-1. In detail, a file containing the published human surfaceome (table_S3_surfaceome.xlsx) was downloaded and merged, using MS excel, with the list of differentially expressed ASPS-1 transcripts. Transcripts appearing in both datasets were then extracted and sorted according to ASPS-1 expression. The VENN diagram utility InteractiVenn (http://www.interactivenn.net/) (Heberle et al. 2015) was used to determine the extent of overlap between the 4 different experimental approaches.

\section{Results and Discussion}

In the first analysis, ASPS-1 exon-level data from the NCI sarcoma cell line panel was analyzed relative to all samples (cancer and normal). Results shown in Table 1 list the top fifty transcripts 
138 over-expressed in ASPS-1 relative to the average (raw data in Supplemental Table 1). Results 139 demonstrated that crystallin alpha beta (CRYAB) mRNA showed the highest expression in ASPS-

1401 relative to the average (227 fold). Metallothionein $1 \mathrm{G}(M T 1 G)$ was the next most elevated (202

141 fold). Following this were several lower-abundance transcripts coding for $C 7$ orf69, Synaptic

142 Vesicle Glycoprotein 2B (SV2B) and Germinal Center-Associated Signaling and Motility-Like

143 Protein $(G C S A M L)$. In common with the initial published report of ASPS-1, results also

144 confirmed expression of GPNMB (Kenney et al. 2011). Likewise, ASPS-1 had some of the

145 highest levels of MET, and VEGFR2 in the panel, both of which are previously noted

146 characteristics of disease (Jun et al. 2010; Stockwin et al. 2009; Tsuda et al. 2007). This analysis

147

148

149 Following this, ASPS-1 was subjected to hierarchical clustering relative to the entire NCI

150

151

152

153

154

155

156

157

158

159

160

161

162

163

164

165

166

167

168

169

170

171

172

173

174

175

176

177

178

179

180

181

182 These data also provide a unique opportunity to assess the potential cell surface phenotype of

183 ASPS-1. Bausch-Fluck et al. identified 2886 proteins that are known, or are predicted by 
184 machine learning, to be expressed on the cell surface (Bausch-Fluck et al. 2018). Here, ASPS-1

185 raw microarray data was filtered for these targets and the list sorted in terms of expression. The

186 resultant ASPS-1 'surfaceome' is shown in Supplemental data 2. As could be anticipated,

$187 G P N M B$ was the highest expressed mRNA; followed by novel surface makers such as the

188 glutamate transporter $S L C 38 A 1$ and the amyloid beta (A4) precursor protein APP. In terms of

189 CD antigens, the following mRNAs were highly expressed in ASPS-1; CD9 (TSPAN29), CD26

190 (DPP4), CD49C (ITGA3), CD54 (ICAM1), CD63 (TSPAN30), CD68 (SCARD1), CD130

191 (IL6ST), CD146 (MCAM), CD147 (BSG), CD151 (SFA-1), CD166 (ALCAM), CD222 (IGF2R),

192

193

194

195

196

197

198

199

200

201

202

203

204

205

206

207

208

209

210

211

212

213

214

215

216

217

218

219

220

221

222

223

224

225

226

227

228

229

Many of these observations are also compatible with a mesenchymal stromal cell. For example, CD9 (TSPAN29) and CD243 (ABCB1), although widely expressed, are found to varying degrees on MSC (Islam et al. 2005; Kim et al. 2007). CD49C (ITGA3) and CD151 (SFA-1) are both markers of chondrogenic differentiation in MSC (Grogan et al. 2007; Lee et al. 2009a) . Expression of CD54 (ICAM1) can be induced in MSC (Ren et al. 2010), CD63 (TSPAN30) is expressed by bone marrow MSC (McBride et al. 2017), CD68 (SCARD1) expression has been shown on MSC from human umbilical cord (La Rocca et al. 2009) and CDH2 is a regulator of mesenchymal stem cell fate (Alimperti \& Andreadis 2015). Exosomes expressing Basigin, BSG (CD147), have been shown to promote angiogenesis in MSC (Vrijsen et al. 2016). CD147 is also a major constituent of the pre-crystalline granules present in ASPS (Ladanyi et al. 2002). Expression of Melanoma Cell Adhesion Molecule, MCAM (CD146), mRNA provides strong evidence for an MSC derivation, with several studies demonstrating an important role for this molecule in MSC maintenance and differentiation (Covas et al. 2008; Espagnolle et al. 2014; Jin et al. 2016; Stopp et al. 2013). Likewise, Activated Leukocyte Cell Adhesion Molecule (ALCAM, CD166), is a recognized marker of MSC and implicated in osteogenesis (Bruder et al. 1998; Hu et al. 2016).

In summary, the results presented here demonstrate that the ASPS- 1 transcriptome is unique amongst the NCI sarcoma panel, where the closest relatives are normal mesenchymal cells and connective tissue sarcomas. Although ASPS-1 has an expression signature with some similarity to skeletal/cardiac muscle tissue, markers of myogenesis were not detected in this cell line. Furthermore, the ASPS- 1 surfaceome does not immediately speak to a tissue derivation but suggests an undifferentiated mesenchymal state.

The next phase of the project involved re-analyzing microarray and RNA-seq data from ASPS tumor resections. GSE13433 comprises microarray data (Affymetrix U133 plus 2.0) for seven patients with primary or metastatic ASPS (Stockwin et al. 2009). In the original study, universal RNA (representing a collection of adult human tissues) was used as a reference. However, patient samples 1,3, 5 and 6 were obtained from skeletal muscle biopsies whereas samples 4 and 7 were isolated from lung. As a consequence, microarray data from normal skeletal muscle and lung represent more appropriate controls. Therefore, skeletal muscle arrays were obtained from GSE17070 and normal lung samples from GSE118370. Patient 2 data, derived from the mandible, was excluded from the analysis for lack of an appropriate control. Two lists of differentially expressed transcripts were then generated for patients $1,3,5,6$ vs skeletal muscle and 4,7 vs. normal lung. Results from these two experiments were largely concordant with the profiles obtained in the original study (Stockwin et al. 2009). However, in Stockwin et al., 
230 muscle-differentiation associated transcripts ITGB1BP3/MIBP, MYF5 and MYF6 were

231

232

233

234

235

236

237

238

239

240

241

242

243

244

245

246

247

248

249

250

251

252

253

254

255

256

257

258

259

260

261

262

263

264

265

266

267

268

269

270

271

272

273

274

275

identified as overexpressed. In our analysis, only MYF6 was identified, and only in the experiment involving patients 4 and 7 vs normal lung; supporting our inference that the published study over-emphasized myogenic differentiation in patient ASPS.

GSE32569 is a similar ASPS dataset where U133 plus 2.0 microarrays were generated from patients treated with Cediranib (Kummar et al. 2013). We undertook to use this data to generate a list of differentially expressed transcripts from pre-treatment arrays relative to GSE17070 skeletal muscle samples. Results again showed a similar profile to that obtained from the analysis of GSE13433. The final experiment was performed using RNA-seq data from GSE54729. In this published study, data was generated from five human ASPS tumor samples in order to compare the transcriptome with five mouse tumors generated through ectopic expression of ASPSCR1-TFE3 (Goodwin et al. 2014). Here, FKPM values for the five human tumors and three skeletal muscle controls were used to generate a list of differentially expressed transcripts. The top fifty upregulated transcripts generated from each of the four experiments using GSE13433, GSE32569 and GSE54729 are shown in Table 2. Meta-analysis of data from these four in vivo studies had considerable overlap, emphasizing the consistent upregulation of mRNAs such as GPNMB, ABCB5, PSG9, CYP17A1, PRL, SULT1C2, and SV2B. As with ASPS1 , over-expression of myogenic regulatory factor mRNA was not consistently seen in any of the experiments involving patient samples (results not shown). Lastly, lists of differentially expressed genes from both ASPS-1 and patient sample experiments were combined (at a fivefold cut-off*), and a VENN diagram generated in order to determine the extent of overlap (Figure 4). Results demonstrated that twenty-five transcripts were elevated in all of the metaanalyses, whereas seventy-three were expressed at the intersection between all in vivo analyses.

An exploration of the twenty-five conserved transcripts in the context of stem cell biology provides further insights into MSC lineage potential. For example; angiopoietin Like 2 (ANGPTL2) is a regulator of stem cell adipogenesis, chondrogenesis and osteogenesis (Takano et al. 2017; Tanoue et al. 2018). Expression of Cathepsin K (CTSK) is compelling given that in mice CTSK-mGFP cells label the periosteal mesenchyme and have been used to identify periosteal stem cells (Debnath et al. 2018). As previously noted, Dipeptidyl Peptidase 4 (DPP4), also known as CD26, marks mesenchymal preadipocyte progenitors (Merrick et al. 2019). Glycoprotein Nmb (GPNMB) should be recognized as the prototypic cell surface marker for ASPS. As stated, GPNMB is recognized as a marker of mesenchymal cells (Kuci et al. 2019). Interestingly, within protein atlas, the cell line designated 'ASC diff', a differentiated adiposederived mesenchymal stem cell line has the highest expression of GPNMB and also expresses TRIM63, CRYAB, FABP3, and CTSK. These observations would appear to favor the concept that ASPS resembles an MSC capable of adipogenic, chondrogenic or osteogenic differentiation.

Several inferences can also be made for the seventy-three conserved transcripts identified in all ASPS patient experiments. The multi-drug resistance transporter ABCB5, in addition to being expressed by melanoma, also defines a subset of MSC in the cornea and skin (Frank et al. 2003; Ksander et al. 2014; Vander Beken et al. 2019). The hormone prolactin (PRL) has been shown to stimulate proliferation of MSC and also to direct chondrogenic and ostegenic differentiation (Ogueta et al. 2002; Seriwatanachai et al. 2012; Surarit et al. 2016). Increased expression of the growth factor midkine (MDK) has been noted in previous ASPS gene expression studies and is

Peer) reviewing PDF | (2020:04:47425:1:1:NEW 20 May 2020) 
276

277

278

279

280

281

282

283

284

285

286

287

288

289

290

291

292

293

294

295

296

297

298

299

300

301

302

303

304

305

306

307

308

309

310

311

312

313

314

315

316

317

318

319

320

321

an MSC survival factor (Stockwin et al. 2009; Zhao et al. 2014). Upregulation of hypoxia-related transcripts such as HIF 1A suggests that this pathway is active in ASPS and, although ubiquitous, HIF1A plays an important role in the control of multipotency for MSC (Palomaki et al. 2013). It was similarly interesting that the ASPS patient experiments showed increased expression of THY1 (CD90) relative to control samples. This target is regarded as a classical marker of MSC and has recently been shown to promote osteogenic differentiation over an adipogenic fate (Saalbach \& Anderegg 2019). In summary, re-analysis of microarray and RNA-seq data for ASPS patient samples yielded transcriptomes with considerable overlap between studies irrespective of platform technology; and the final consensus ASPS transcriptome resembles an undifferentiated mesenchymal stromal cell.

*A supplemental dataset (file 3) is also provided that comprises low-stringency (2-fold) expression data provided so that any gene of interest can also be analyzed for expression over the entire set of experiments.

Conclusions

Alveolar-soft part sarcoma is an example of a malignancy that has, despite several immunohistochemical and genomics studies, evaded classification (Fisher \& Reidbord 1971; Folpe \& Deyrup 2006; Gomez et al. 1999; Goodwin et al. 2014; Hoshino et al. 2009; Mukai et al. 1983; Selvarajah et al. 2014; Stockwin et al. 2009; Tallini et al. 1994; Tanaka et al. 2017; Wang et al. 1996). This study was prompted by the public release of exon expression data for the cell line ASPS-1, which offers a unique opportunity to study ASPS in isolation (Kenney et al. 2011; Teicher et al. 2015). We were similarly interested in revisiting the genomic studies of ourselves and others to generate a consensus expression profile independent of platform technology.

The central finding of the current study was that the ASPS transcriptome is indicative of an undifferentiated mesenchymal stromal cell (MSC). Specifically, The ASPS-1 cell line exhibited a mesenchymal expression signature, where expression data clustered with normal and malignant mesenchymal cells within the NCI sarcoma cell line panel. The ASPS-1 surfaceome was similarly suggestive of an undifferentiated mesenchymal cell. Generation of an ASPS consensus transcriptome from previously reported patient studies highlighted the importance of targets such as $G P N M B, A B C B 5, C S T K, D P P 4, B S G, A L C A M, P R L$, and $C D H N$; all of which were consistent with an undifferentiated MSC. Conversely, the ASPS transcriptome lacked expression of myogenesis-related genes and did not feature transcripts indicative of neural, pericyte or endothelial differentiation.

MSC are found in most tissues, these cells are capable of multipotent differentiation into bone, muscle, cartilage, adipocytes, marrow stromal cells, tenocytes, fibroblasts, endothelial and neural cells (Caplan 2007; Pittenger et al. 2019). Tissues maintain a pool of MSC, with varying degrees of specialization, ready to dynamically replenish differentiated cells in response to signals associated with growth, homeostasis or damage (Rubenstein et al. 2020). Prior to this study, ASPL-TFE3 had already been shown to immortalize embryonic mesenchymal cells (Tanaka et al. 2017). The suggestion that ASPS resembles a mesenchymal stromal progenitor provides a plausible explanation for the failure of previous studies to pinpoint cellular origin, given that the

Peer) reviewing PDF | (2020:04:47425:1:1:NEW 20 May 2020) 
322 cell retains an undifferentiated state. Evidence from this study favors an MSC capable of

323 adipogenic, osteogenic or chondrogenic differentiation, but not necessarily at the exclusion of

324 other lineages.

325

326

327

328

329

330

331

332

333

334

335

336

337

338

339

340

341

342

343

344

345

346

347

348

349

350

351

352

353

354

355

356

357

358

359

360

361

362

363

364

365

366

367

If an MSC origin for ASPS could ultimately be confirmed, there would be important consequences for therapeutic development. Foremost is the suggestion that ASPS growth may be inhibited by factors that promote MSC differentiation. For example, several high-throughput studies have identified clinically relevant small molecules capable of promoting or inhibiting differentiation of MSC (Brey et al. 2011; Huang et al. 2008). Re-screening these compounds for their ability to inhibit the growth of ASPS-1 may yield clinically tractable candidates for ASPS treatment. From the authors perspective, the effect of HDAC inhibitors, steroids and retinoids on ASPS-1 growth are of particular interest (Lee et al. 2009b; Salloum et al. 2013).

The findings of this study have a central caveat; all speculation regarding cellular origin must be moderated until the inference of ASPL-TFE3 is removed. Given the ability of this fusion protein to re-direct transcription, the observed transcriptomes may mask the true cellular origin. For example, GPNMB, CRYAB, CYP17A1, SULT1C2, UPP1 and SV2B have been shown to be upregulated following expression of ASPL-TFE3 in inducible 293 cells (Kobos et al. 2013). Therefore, the current study only suggests that ASPS resembles an MSC and no firm conclusion can be made regarding origin. A straightforward approach to address this central question involves generating an ASPL-TFE3 knockout in ASPS-1 perhaps with re-introduction of wildtype TFE3 to maintain viability. The resultant line could then be characterized by RNA-seq and FACS phenotyping. These experiments could be accompanied by the addition of defined media to determine whether differentiation can be directed toward specific MSC lineages. In the interim, the data presented here provides a unified picture of ASPS mRNA expression, where considerable similarity with mesenchymal stromal progenitors is evident.

Acknowledgments

I would like to thank Dr. Francesco Tomassoni, Dr. C. Andrew Stewart and Marie Stockwin, PAC for scientific and editorial input.

References

Alimperti S, and Andreadis ST. 2015. CDH2 and CDH11 act as regulators of stem cell fate decisions. Stem Cell Res 14:270-282. 10.1016/j.scr.2015.02.002

Argani P, Lal P, Hutchinson B, Lui MY, Reuter VE, and Ladanyi M. 2003. Aberrant nuclear immunoreactivity for TFE3 in neoplasms with TFE3 gene fusions: a sensitive and specific immunohistochemical assay. Am J Surg Pathol 27:750-761. 10.1097/00000478200306000-00005

Bausch-Fluck D, Goldmann U, Muller S, van Oostrum M, Muller M, Schubert OT, and Wollscheid B. 2018. The in silico human surfaceome. Proc Natl Acad Sci U S A 115:E10988-E10997. 10.1073/pnas. 1808790115

Betschinger J, Nichols J, Dietmann S, Corrin PD, Paddison PJ, and Smith A. 2013. Exit from pluripotency is gated by intracellular redistribution of the bHLH transcription factor Tfe3. Cell 153:335-347. 10.1016/j.cell.2013.03.012 
368

369

370

371

372

373

374

375

376

377

378

379

380

381

382

383

384

385

386

387

388

389

390

391

392

393

394

395

396

397

398

399

400

401

402

403

404

405

406

407

408

409

410

411

412

Brey DM, Motlekar NA, Diamond SL, Mauck RL, Garino JP, and Burdick JA. 2011. Highthroughput screening of a small molecule library for promoters and inhibitors of mesenchymal stem cell osteogenic differentiation. Biotechnol Bioeng 108:163-174. $10.1002 /$ bit. 22925

Bruder SP, Ricalton NS, Boynton RE, Connolly TJ, Jaiswal N, Zaia J, and Barry FP. 1998. Mesenchymal stem cell surface antigen SB-10 corresponds to activated leukocyte cell adhesion molecule and is involved in osteogenic differentiation. J Bone Miner Res 13:655663. 10.1359/jbmr.1998.13.4.655

Caplan AI. 2007. Adult mesenchymal stem cells for tissue engineering versus regenerative medicine. J Cell Physiol 213:341-347. 10.1002/jcp.21200

Christopherson WM, Foote FW, Jr., and Stewart FW. 1952. Alveolar soft-part sarcomas; structurally characteristic tumors of uncertain histogenesis. Cancer 5:100-111. 10.1002/1097-0142(195201)5:1<100::aid-cncr2820050112>3.0.co;2-k

Covas DT, Panepucci RA, Fontes AM, Silva WA, Jr., Orellana MD, Freitas MC, Neder L, Santos AR, Peres LC, Jamur MC, and Zago MA. 2008. Multipotent mesenchymal stromal cells obtained from diverse human tissues share functional properties and gene-expression profile with CD146+ perivascular cells and fibroblasts. Exp Hematol 36:642-654. 10.1016/j.exphem.2007.12.015

Debnath S, Yallowitz AR, McCormick J, Lalani S, Zhang T, Xu R, Li N, Liu Y, Yang YS, Eiseman M, Shim JH, Hameed M, Healey JH, Bostrom MP, Landau DA, and Greenblatt MB. 2018. Discovery of a periosteal stem cell mediating intramembranous bone formation. Nature 562:133-139. 10.1038/s41586-018-0554-8

Dohi Y, Shimaoka H, Ikeuchi M, Ohgushi H, Yonemasu K, and Minami T. 2005. Role of metallothionein isoforms in bone formation processes in rat marrow mesenchymal stem cells in culture. Biol Trace Elem Res 104:57-70. 10.1385/BTER:104:1:057

Espagnolle N, Guilloton F, Deschaseaux F, Gadelorge M, Sensebe L, and Bourin P. 2014. CD146 expression on mesenchymal stem cells is associated with their vascular smooth muscle commitment. J Cell Mol Med 18:104-114. 10.1111/jcmm.12168

Fisher ER, and Reidbord H. 1971. Electron microscopic evidence suggesting the myogenous derivation of the so-called alveolar soft part sarcoma. Cancer 27:150-159. 10.1002/10970142(197101)27:1<150::aid-cncr2820270123>3.0.co;2-0

Folpe AL, and Deyrup AT. 2006. Alveolar soft-part sarcoma: a review and update. J Clin Pathol 59:1127-1132. 10.1136/jcp.2005.031120

Frank NY, Pendse SS, Lapchak PH, Margaryan A, Shlain D, Doeing C, Sayegh MH, and Frank MH. 2003. Regulation of progenitor cell fusion by ABCB5 P-glycoprotein, a novel human ATP-binding cassette transporter. $J$ Biol Chem 278:47156-47165. 10.1074/jbc.M308700200

Gomez JA, Amin MB, Ro JY, Linden MD, Lee MW, and Zarbo RJ. 1999. Immunohistochemical profile of myogenin and MyoD1 does not support skeletal muscle lineage in alveolar soft part sarcoma. Arch Pathol Lab Med 123:503-507. 10.1043/00039985(1999)123<0503:IPOMAM >2.0.CO;2

Goodwin ML, Jin H, Straessler K, Smith-Fry K, Zhu JF, Monument MJ, Grossmann A, Randall RL, Capecchi MR, and Jones KB. 2014. Modeling alveolar soft part sarcomagenesis in the mouse: a role for lactate in the tumor microenvironment. Cancer Cell 26:851-862. 10.1016/j.ccell.2014.10.003

Peer) reviewing PDF | (2020:04:47425:1:1:NEW 20 May 2020) 
413 Grogan SP, Barbero A, Diaz-Romero J, Cleton-Jansen AM, Soeder S, Whiteside R, Hogendoorn 414 PC, Farhadi J, Aigner T, Martin I, and Mainil-Varlet P. 2007. Identification of markers to

415

416

417

418

419

420

421

422

423

424

425

426

427

428

429

430

431

432

433

434

435

436

437

438

439

440

441

442

443

444

445

446

447

448

449

450

451

452

453

454

455

456

457

458 characterize and sort human articular chondrocytes with enhanced in vitro chondrogenic capacity. Arthritis Rheum 56:586-595. 10.1002/art.22408

Hayman AR, Bune AJ, Bradley JR, Rashbass J, and Cox TM. 2000. Osteoclastic tartrate-resistant acid phosphatase (Acp 5): its localization to dendritic cells and diverse murine tissues. $J$ Histochem Cytochem 48:219-228. 10.1177/002215540004800207

Heberle H, Meirelles GV, da Silva FR, Telles GP, and Minghim R. 2015. InteractiVenn: a webbased tool for the analysis of sets through Venn diagrams. BMC Bioinformatics 16:169. 10.1186/s12859-015-0611-3

Hirobe M, Masumori N, Tanaka T, Kitamura H, and Tsukamoto T. 2013. Establishment of an ASPL-TFE3 renal cell carcinoma cell line (S-TFE). Cancer Biol Ther 14:502-510. $10.4161 /$ cbt. 24344

Hortells L, Johansen AKZ, and Yutzey KE. 2019. Cardiac Fibroblasts and the Extracellular Matrix in Regenerative and Nonregenerative Hearts. $J$ Cardiovasc Dev Dis 6. $10.3390 /$ jcdd6030029

Hoshino M, Ogose A, Kawashima H, Izumi T, Hotta T, Hatano H, Morita T, Otsuka H, Umezu H, Yanoma S, Tsukuda M, and Endo N. 2009. Molecular analyses of cell origin and detection of circulating tumor cells in the peripheral blood in alveolar soft part sarcoma. Cancer Genet Cytogenet 190:75-80. 10.1016/j.cancergencyto.2008.11.014

Hu X, Garcia M, Weng L, Jung X, Murakami JL, Kumar B, Warden CD, Todorov I, and Chen CC. 2016. Identification of a common mesenchymal stromal progenitor for the adult haematopoietic niche. Nat Commun 7:13095. 10.1038/ncomms13095

Huang AH, Motlekar NA, Stein A, Diamond SL, Shore EM, and Mauck RL. 2008. Highthroughput screening for modulators of mesenchymal stem cell chondrogenesis. Ann Biomed Eng 36:1909-1921. 10.1007/s10439-008-9562-4

Islam MO, Kanemura Y, Tajria J, Mori H, Kobayashi S, Shofuda T, Miyake J, Hara M, Yamasaki M, and Okano H. 2005. Characterization of ABC transporter ABCB1 expressed in human neural stem/progenitor cells. FEBS Lett 579:3473-3480. 10.1016/j.febslet.2005.05.019

Jiang D, and Rinkevich Y. 2018. Defining Skin Fibroblastic Cell Types Beyond CD90. Front Cell Dev Biol 6:133. 10.3389/fcell.2018.00133

Jin HJ, Kwon JH, Kim M, Bae YK, Choi SJ, Oh W, Yang YS, and Jeon HB. 2016. Downregulation of Melanoma Cell Adhesion Molecule (MCAM/CD146) Accelerates Cellular Senescence in Human Umbilical Cord Blood-Derived Mesenchymal Stem Cells. Stem Cells Transl Med 5:427-439. 10.5966/sctm.2015-0109

Jun HJ, Lee J, Lim DH, Park JO, Ahn G, Seo SW, Sung KS, Lim DH, Yoo KH, and Choi YL. 2010. Expression of MET in alveolar soft part sarcoma. Med Oncol 27:459-465. 10.1007/s12032-009-9234-8

Karagiannis GS, Poutahidis T, Erdman SE, Kirsch R, Riddell RH, and Diamandis EP. 2012. Cancer-associated fibroblasts drive the progression of metastasis through both paracrine and mechanical pressure on cancer tissue. Mol Cancer Res 10:1403-1418. 10.1158/15417786.MCR-12-0307

Kenney S, Vistica DT, Stockwin LH, Burkett S, Hollingshead MG, Borgel SD, Butcher DO, Schrump DS, and Shoemaker RH. 2011. ASPS-1, a novel cell line manifesting key features of alveolar soft part sarcoma. $J$ Pediatr Hematol Oncol 33:360-368. 10.1097/MPH.0b013e3182002f9f

Peer] reviewing PDF | (2020:04:47425:1:1:NEW 20 May 2020) 
459

460

461

462

463

464

465

466

467

468

469

470

471

472

473

474

475

476

477

478

479

480

481

482

483

484

485

486

487

488

489

490

491

492

493

494

495

496

497

498

499

500

501

502

503

Kim YJ, Yu JM, Joo HJ, Kim HK, Cho HH, Bae YC, and Jung JS. 2007. Role of CD9 in proliferation and proangiogenic action of human adipose-derived mesenchymal stem cells. Pflugers Arch 455:283-296. 10.1007/s00424-007-0285-4

Kobos R, Nagai M, Tsuda M, Merl MY, Saito T, Lae M, Mo Q, Olshen A, Lianoglou S, Leslie C, Ostrovnaya I, Antczak C, Djaballah H, and Ladanyi M. 2013. Combining integrated genomics and functional genomics to dissect the biology of a cancer-associated, aberrant transcription factor, the ASPSCR1-TFE3 fusion oncoprotein. $J$ Pathol 229:743-754. $10.1002 /$ path. 4158

Ksander BR, Kolovou PE, Wilson BJ, Saab KR, Guo Q, Ma J, McGuire SP, Gregory MS, Vincent WJ, Perez VL, Cruz-Guilloty F, Kao WW, Call MK, Tucker BA, Zhan Q, Murphy GF, Lathrop KL, Alt C, Mortensen LJ, Lin CP, Zieske JD, Frank MH, and Frank NY. 2014. ABCB5 is a limbal stem cell gene required for corneal development and repair. Nature 511:353-357. 10.1038/nature13426

Kuci S, Kuci Z, Schafer R, Spohn G, Winter S, Schwab M, Salzmann-Manrique E, Klingebiel T, and Bader P. 2019. Molecular signature of human bone marrow-derived mesenchymal stromal cell subsets. Sci Rep 9:1774. 10.1038/s41598-019-38517-7

Kulterer B, Friedl G, Jandrositz A, Sanchez-Cabo F, Prokesch A, Paar C, Scheideler M, Windhager R, Preisegger KH, and Trajanoski Z. 2007. Gene expression profiling of human mesenchymal stem cells derived from bone marrow during expansion and osteoblast differentiation. BMC Genomics 8:70. 10.1186/1471-2164-8-70

Kummar S, Allen D, Monks A, Polley EC, Hose CD, Ivy SP, Turkbey IB, Lawrence S, Kinders RJ, Choyke P, Simon R, Steinberg SM, Doroshow JH, and Helman L. 2013. Cediranib for metastatic alveolar soft part sarcoma. $J$ Clin Oncol 31:2296-2302. 10.1200/JCO.2012.47.4288

La Rocca G, Anzalone R, and Farina F. 2009. The expression of CD68 in human umbilical cord mesenchymal stem cells: new evidences of presence in non-myeloid cell types. Scand $J$ Immunol 70:161-162. 10.1111/j.1365-3083.2009.02283.x

Ladanyi M, Antonescu CR, Drobnjak M, Baren A, Lui MY, Golde DW, and Cordon-Cardo C. 2002. The precrystalline cytoplasmic granules of alveolar soft part sarcoma contain monocarboxylate transporter 1 and CD147. Am J Pathol 160:1215-1221. 10.1016/S00029440(10)62548-5

Ladanyi M, Lui MY, Antonescu CR, Krause-Boehm A, Meindl A, Argani P, Healey JH, Ueda T, Yoshikawa H, Meloni-Ehrig A, Sorensen PH, Mertens F, Mandahl N, van den Berghe H, Sciot R, Dal Cin P, and Bridge J. 2001. The der(17)t(X;17)(p11;q25) of human alveolar soft part sarcoma fuses the TFE3 transcription factor gene to ASPL, a novel gene at 17q25. Oncogene 20:48-57. 10.1038/sj.onc. 1204074

Lee HJ, Choi BH, Min BH, and Park SR. 2009a. Changes in surface markers of human mesenchymal stem cells during the chondrogenic differentiation and dedifferentiation processes in vitro. Arthritis Rheum 60:2325-2332. 10.1002/art.24786

Lee S, Park JR, Seo MS, Roh KH, Park SB, Hwang JW, Sun B, Seo K, Lee YS, Kang SK, Jung JW, and Kang KS. 2009b. Histone deacetylase inhibitors decrease proliferation potential and multilineage differentiation capability of human mesenchymal stem cells. Cell Prolif 42:711-720. 10.1111/j.1365-2184.2009.00633.x

McBride JD, Rodriguez-Menocal L, Guzman W, Candanedo A, Garcia-Contreras M, and Badiavas EV. 2017. Bone Marrow Mesenchymal Stem Cell-Derived CD63(+) Exosomes

Peer) reviewing PDF | (2020:04:47425:1:1:NEW 20 May 2020) 
504

505

506

507

508

509

510

511

512

513

514

515

516

517

518

519

520

521

522

523

524

525

526

527

528

529

530

531

532

533

534

535

536

537

538

539

540

541

542

543

544

545

546

547

548

549

Transport Wnt3a Exteriorly and Enhance Dermal Fibroblast Proliferation, Migration, and Angiogenesis In Vitro. Stem Cells Dev 26:1384-1398. 10.1089/scd.2017.0087

Merrick D, Sakers A, Irgebay Z, Okada C, Calvert C, Morley MP, Percec I, and Seale P. 2019. Identification of a mesenchymal progenitor cell hierarchy in adipose tissue. Science 364. 10.1126/science.aav2501

Moller AMJ, Fuchtbauer EM, Bruel A, Andersen TL, Borggaard XG, Pavlos NJ, Thomsen JS, Pedersen FS, Delaisse JM, and Soe K. 2018. Septins are critical regulators of osteoclastic bone resorption. Sci Rep 8:13016. 10.1038/s41598-018-31159-1

Mukai M, Iri H, Nakajima T, Hirose S, Torikata C, Kageyama K, Ueno N, and Murakami K. 1983. Alveolar soft-part sarcoma. A review on its histogenesis and further studies based on electron microscopy, immunohistochemistry, and biochemistry. Am J Surg Pathol 7:679689.

Naka A, Iida KT, Nakagawa Y, Iwasaki H, Takeuchi Y, Satoh A, Matsuzaka T, Ishii KA, Kobayashi K, Yatoh S, Shimada M, Yahagi N, Suzuki H, Sone H, Yamada N, and Shimano H. 2013. TFE3 inhibits myoblast differentiation in C2C12 cells via down-regulating gene expression of myogenin. Biochem Biophys Res Commun 430:664-669. 10.1016/j.bbrc.2012.11.094

Ogueta S, Munoz J, Obregon E, Delgado-Baeza E, and Garcia-Ruiz JP. 2002. Prolactin is a component of the human synovial liquid and modulates the growth and chondrogenic differentiation of bone marrow-derived mesenchymal stem cells. Mol Cell Endocrinol 190:51-63. 10.1016/s0303-7207(02)00013-8

Palomaki S, Pietila M, Laitinen S, Pesala J, Sormunen R, Lehenkari P, and Koivunen P. 2013. HIF-1alpha is upregulated in human mesenchymal stem cells. Stem Cells 31:1902-1909. 10.1002/stem.1435

Paoluzzi L, and Maki RG. 2019. Diagnosis, Prognosis, and Treatment of Alveolar Soft-Part Sarcoma: A Review. JAMA Oncol 5:254-260. 10.1001/jamaoncol.2018.4490

Pittenger MF, Discher DE, Peault BM, Phinney DG, Hare JM, and Caplan AI. 2019. Mesenchymal stem cell perspective: cell biology to clinical progress. NPJ Regen Med 4:22. 10.1038/s41536-019-0083-6

Portera CA, Jr., Ho V, Patel SR, Hunt KK, Feig BW, Respondek PM, Yasko AW, Benjamin RS, Pollock RE, and Pisters PW. 2001. Alveolar soft part sarcoma: clinical course and patterns of metastasis in 70 patients treated at a single institution. Cancer 91:585-591. 10.1002/1097-0142(20010201)91:3<585::aid-cncr1038>3.0.co;2-0

Ren G, Zhao X, Zhang L, Zhang J, L'Huillier A, Ling W, Roberts AI, Le AD, Shi S, Shao C, and Shi Y. 2010. Inflammatory cytokine-induced intercellular adhesion molecule-1 and vascular cell adhesion molecule-1 in mesenchymal stem cells are critical for immunosuppression. J Immunol 184:2321-2328. 10.4049/jimmunol.0902023

Rubenstein AB, Smith GR, Raue U, Begue G, Minchev K, Ruf-Zamojski F, Nair VD, Wang X, Zhou L, Zaslavsky E, Trappe TA, Trappe S, and Sealfon SC. 2020. Single-cell transcriptional profiles in human skeletal muscle. Sci Rep 10:229. 10.1038/s41598-01957110-6

Saalbach A, and Anderegg U. 2019. Thy-1: more than a marker for mesenchymal stromal cells. FASEB J 33:6689-6696. 10.1096/fj.201802224R

Salloum RH, Rubin JP, and Marra KG. 2013. The role of steroids in mesenchymal stem cell differentiation: molecular and clinical perspectives. Horm Mol Biol Clin Investig 14:3-14. 10.1515/hmbci-2013-0016 
550

551

552

553

554

555

556

557

558

559

560

561

562

563

564

565

566

567

568

569

570

571

572

573

574

575

576

577

578

579

580

581

582

583

584

585

586

587

588

589

590

591

592

593

594

Schoffski P, Wozniak A, Kasper B, Aamdal S, Leahy MG, Rutkowski P, Bauer S, Gelderblom H, Italiano A, Lindner LH, Hennig I, Strauss S, Zakotnik B, Anthoney A, Albiges L, Blay JY, Reichardt P, Sufliarsky J, van der Graaf WTA, Debiec-Rychter M, Sciot R, Van Cann T, Marreaud S, Raveloarivahy T, Collette S, and Stacchiotti S. 2018. Activity and safety of crizotinib in patients with alveolar soft part sarcoma with rearrangement of TFE3: European Organization for Research and Treatment of Cancer (EORTC) phase II trial 90101 'CREATE'. Ann Oncol 29:758-765. 10.1093/annonc/mdx774

Selvarajah S, Pyne S, Chen E, Sompallae R, Ligon AH, Nielsen GP, Dranoff G, Stack E, Loda M, and Flavin R. 2014. High-resolution array CGH and gene expression profiling of alveolar soft part sarcoma. Clin Cancer Res 20:1521-1530. 10.1158/1078-0432.CCR-13-2090

Seriwatanachai D, Krishnamra N, and Charoenphandhu N. 2012. Chondroregulatory action of prolactin on proliferation and differentiation of mouse chondrogenic ATDC5 cells in 3dimensional micromass cultures. Biochem Biophys Res Commun 420:108-113. 10.1016/j.bbrc.2012.02.123

Stockwin LH, Vistica DT, Kenney S, Schrump DS, Butcher DO, Raffeld M, and Shoemaker RH. 2009. Gene expression profiling of alveolar soft-part sarcoma (ASPS). BMC Cancer 9:22. 10.1186/1471-2407-9-22

Stopp S, Bornhauser M, Ugarte F, Wobus M, Kuhn M, Brenner S, and Thieme S. 2013. Expression of the melanoma cell adhesion molecule in human mesenchymal stromal cells regulates proliferation, differentiation, and maintenance of hematopoietic stem and progenitor cells. Haematologica 98:505-513. 10.3324/haematol.2012.065201

Surarit R, Krishnamra N, and Seriwatanachai D. 2016. Prolactin receptor and osteogenic induction of prolactin in human periodontal ligament fibroblasts. Cell Biol Int 40:419-427. 10.1002/cbin. 10580

Takano A, Fukuda T, Shinjo T, Iwashita M, Matsuzaki E, Yamamichi K, Takeshita M, Sanui T, and Nishimura F. 2017. Angiopoietin-like protein 2 is a positive regulator of osteoblast differentiation. Metabolism 69:157-170. 10.1016/j.metabol.2017.01.006

Tallini G, Parham DM, Dias P, Cordon-Cardo C, Houghton PJ, and Rosai J. 1994. Myogenic regulatory protein expression in adult soft tissue sarcomas. A sensitive and specific marker of skeletal muscle differentiation. Am J Pathol 144:693-701.

Tan SL, Ahmad TS, Ng WM, Azlina AA, Azhar MM, Selvaratnam L, and Kamarul T. 2015. Identification of Pathways Mediating Growth Differentiation Factor5-Induced Tenogenic Differentiation in Human Bone Marrow Stromal Cells. PLoS One 10:e0140869. 10.1371/journal.pone.0140869

Tanaka M, Homme M, Yamazaki Y, Shimizu R, Takazawa Y, and Nakamura T. 2017. Modeling Alveolar Soft Part Sarcoma Unveils Novel Mechanisms of Metastasis. Cancer Res 77:897907. 10.1158/0008-5472.CAN-16-2486

Tanoue H, Morinaga J, Yoshizawa T, Yugami M, Itoh H, Nakamura T, Uehara Y, Masuda T, Odagiri H, Sugizaki T, Kadomatsu T, Miyata K, Endo M, Terada K, Ochi H, Takeda S, Yamagata K, Fukuda T, Mizuta H, and Oike Y. 2018. Angiopoietin-like protein 2 promotes chondrogenic differentiation during bone growth as a cartilage matrix factor. Osteoarthritis Cartilage 26:108-117. 10.1016/j.joca.2017.10.011

Teicher BA, Polley E, Kunkel M, Evans D, Silvers T, Delosh R, Laudeman J, Ogle C, Reinhart R, Selby M, Connelly J, Harris E, Monks A, and Morris J. 2015. Sarcoma Cell Line Screen of Oncology Drugs and Investigational Agents Identifies Patterns Associated with Gene

Peer) reviewing PDF | (2020:04:47425:1:1:NEW 20 May 2020) 
602

603

604

605

606

607

608

609

610

611

612

613

614

615

616

617

618

619

620

621

622

623

624

625

626

627 and microRNA Expression. Mol Cancer Ther 14:2452-2462. 10.1158/1535-7163.MCT15-0074

Tsuda M, Davis IJ, Argani P, Shukla N, McGill GG, Nagai M, Saito T, Lae M, Fisher DE, and Ladanyi M. 2007. TFE3 fusions activate MET signaling by transcriptional up-regulation, defining another class of tumors as candidates for therapeutic MET inhibition. Cancer Res 67:919-929. 10.1158/0008-5472.CAN-06-2855

Vander Beken S, de Vries JC, Meier-Schiesser B, Meyer P, Jiang D, Sindrilaru A, Ferreira FF, Hainzl A, Schatz S, Muschhammer J, Scheurmann NJ, Kampilafkos P, Seitz AM, Durselen L, Ignatius A, Kluth MA, Ganss C, Wlaschek M, Singh K, Maity P, Frank NY, Frank MH, and Scharffetter-Kochanek K. 2019. Newly Defined ATP-Binding Cassette Subfamily B Member 5 Positive Dermal Mesenchymal Stem Cells Promote Healing of Chronic IronOverload Wounds via Secretion of Interleukin-1 Receptor Antagonist. Stem Cells 37:10571074. 10.1002/stem.3022

Vrijsen KR, Maring JA, Chamuleau SA, Verhage V, Mol EA, Deddens JC, Metz CH, Lodder K, van Eeuwijk EC, van Dommelen SM, Doevendans PA, Smits AM, Goumans MJ, and Sluijter JP. 2016. Exosomes from Cardiomyocyte Progenitor Cells and Mesenchymal Stem Cells Stimulate Angiogenesis Via EMMPRIN. Adv Healthc Mater 5:2555-2565. 10.1002/adhm.201600308

Wang NP, Bacchi CE, Jiang JJ, McNutt MA, and Gown AM. 1996. Does alveolar soft-part sarcoma exhibit skeletal muscle differentiation? An immunocytochemical and biochemical study of myogenic regulatory protein expression. Mod Pathol 9:496-506.

Wang S, Zhou Y, Andreyev O, Hoyt RF, Jr., Singh A, Hunt T, and Horvath KA. 2014. Overexpression of FABP3 inhibits human bone marrow derived mesenchymal stem cell proliferation but enhances their survival in hypoxia. Exp Cell Res 323:56-65. 10.1016/j.yexcr.2014.02.015

Yu B, Sondag GR, Malcuit C, Kim MH, and Safadi FF. 2016. Macrophage-Associated Osteoactivin/GPNMB Mediates Mesenchymal Stem Cell Survival, Proliferation, and Migration Via a CD44-Dependent Mechanism. J Cell Biochem 117:1511-1521. 10.1002/jcb.25394

Zhao SL, Zhang YJ, Li MH, Zhang XL, and Chen SL. 2014. Mesenchymal stem cells with overexpression of midkine enhance cell survival and attenuate cardiac dysfunction in a rat model of myocardial infarction. Stem Cell Res Ther 5:37. 10.1186/scrt425 


\section{Figure 1}

\section{Study Design}

This study focuses on the analysis of four publicly available GEO gene-expression datasets.

GSE68591 comprises exon level expression data for the NCl sarcoma cell line panel, which includes data for the ASPS cell line ASPS-1. The remaining three studies comprise transcriptomic data for ASPS patient samples. GSE13433 comprises Affymetrix U133 plus 2.0 microarray data from our initial gene expression study of seven ASPS patients. GSE32569 uses the same array platform to study ASPS patient sample responses to Cedirinib. Lastly, GSE54729 comprises Illumina HISeq 2000 RNA-seq data for ASPS patient samples generated as part of an ASPS mouse modeling study. These data were re-analyzed using appropriate controls in order to generate a consensus transcriptome and gain insights into ASPS pathobiology. 


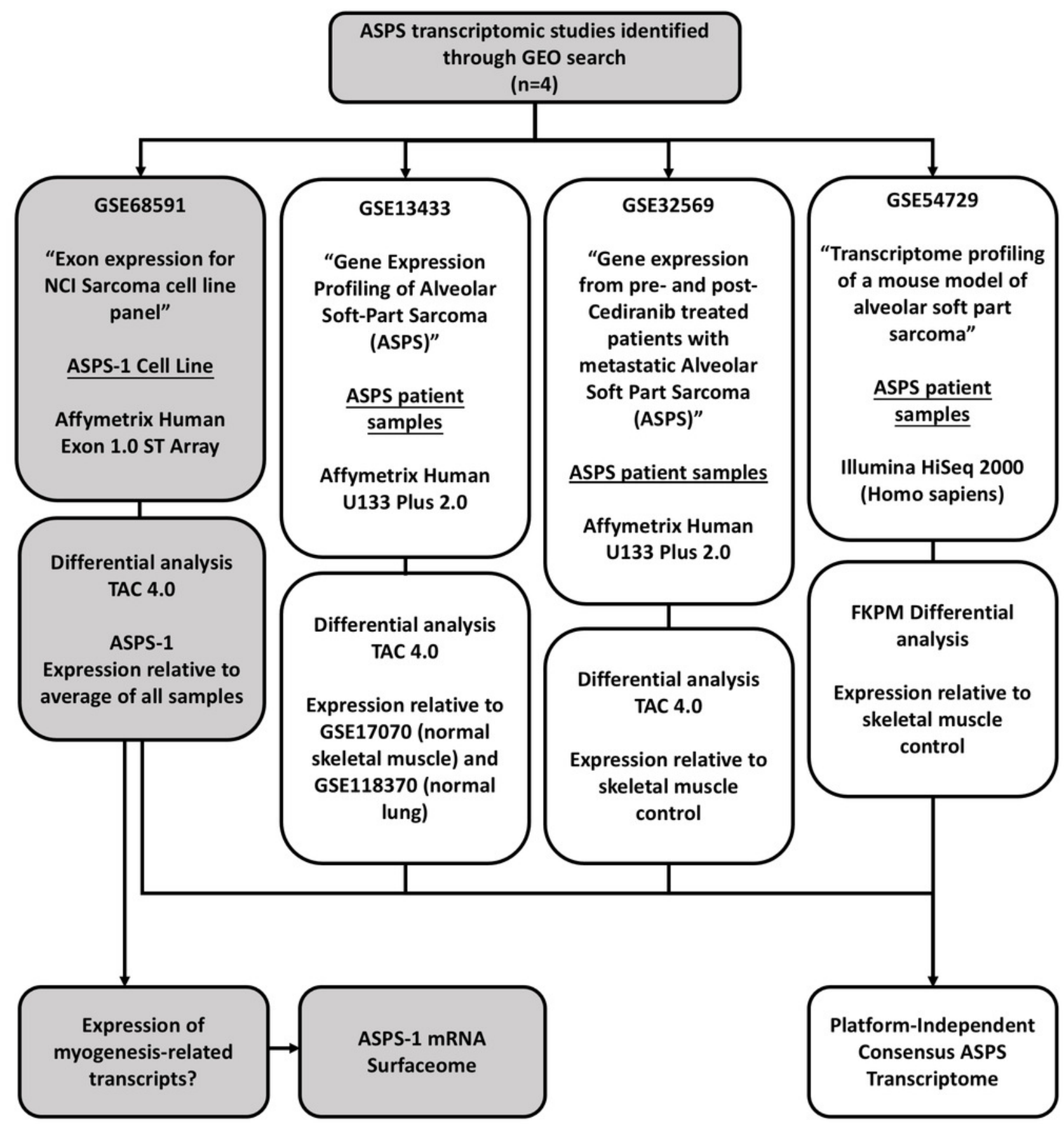


Figure 2

Analysis of ASPS-1 transcriptomic data.

(A) Heirarchical clustering of the $\mathrm{NCl}$ sarcoma cell line panel exon array data (B) tissue or tumor derivation for cluster nearest ASPS-1. (C) GTEX tissue of origin analysis for top fifty ASPS-1 transcripts.

A
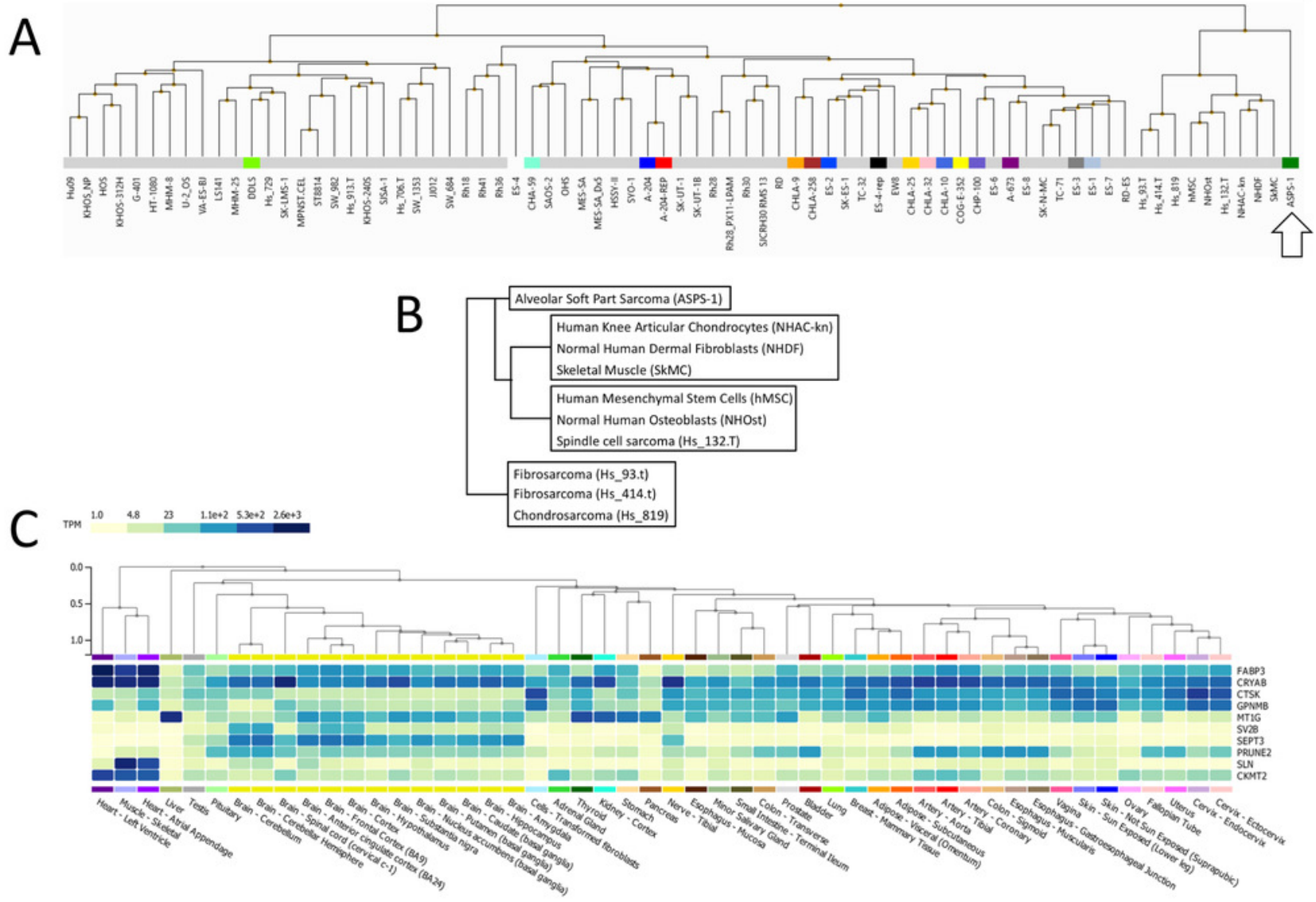


\section{Figure 3}

Expression of myogenesis-related transcripts in ASPS-1 relative to the other sarcoma cell lines

Cell lines in the $\mathrm{NCl}$ sarcoma panel were segregated according to disease type and the average of exon expression data plotted for transcripts encoding myogenesis-related transcription factors and muscle structural proteins. ASPS- 1 data is shown first; then RMS = Rhabdomyosarcoma, RT = Rhabdoid tumor, LMS = Leiomyosarcoma, $\mathrm{CS}=$ Chondrosarcoma, FS = Fibrosarcoma, EWS = Ewings Sarcoma, OS = Osteosarcoma, SS = Synovial Sarcoma, US = Uterine Sarcoma, SNOS = Sarcoma not otherwise specified, GCS = Giant cell sarcoma, MNS = Malignant peripheral nerve sheath, LPS = Liposarcoma, SPS = Spindle cell sarcoma, $\mathrm{EP}=$ Epithelioid, $\mathrm{NC}=$ Normal cells, SkMc $=$ skeletal muscle cells. For transcripts; MYF5 = Myogenic Factor 5, MYF6 = Myogenic Factor 6, MYOD1 = Myogenic Differentiation 1, MYOG = Myogenin, $P A X 3=$ Paired Box 3,PAX7 = Paired Box 7. Structural proteins; $D E S=$ desmin, NEB $=$ nebulin, $T N N T 1=$ Troponin T1 - Slow Skeletal Type, $T R I M 63=$ Tripartite Motif Containing $63, T T N=$ titin and MSTN = Myostatin. Transcripts evaluated but not shown included; EYA1, LBX1, MEF2B, MEOX2, MITF, MSX1, PITX1, SIM2, SIX1, SIX4, TFE3 and TFEB. 


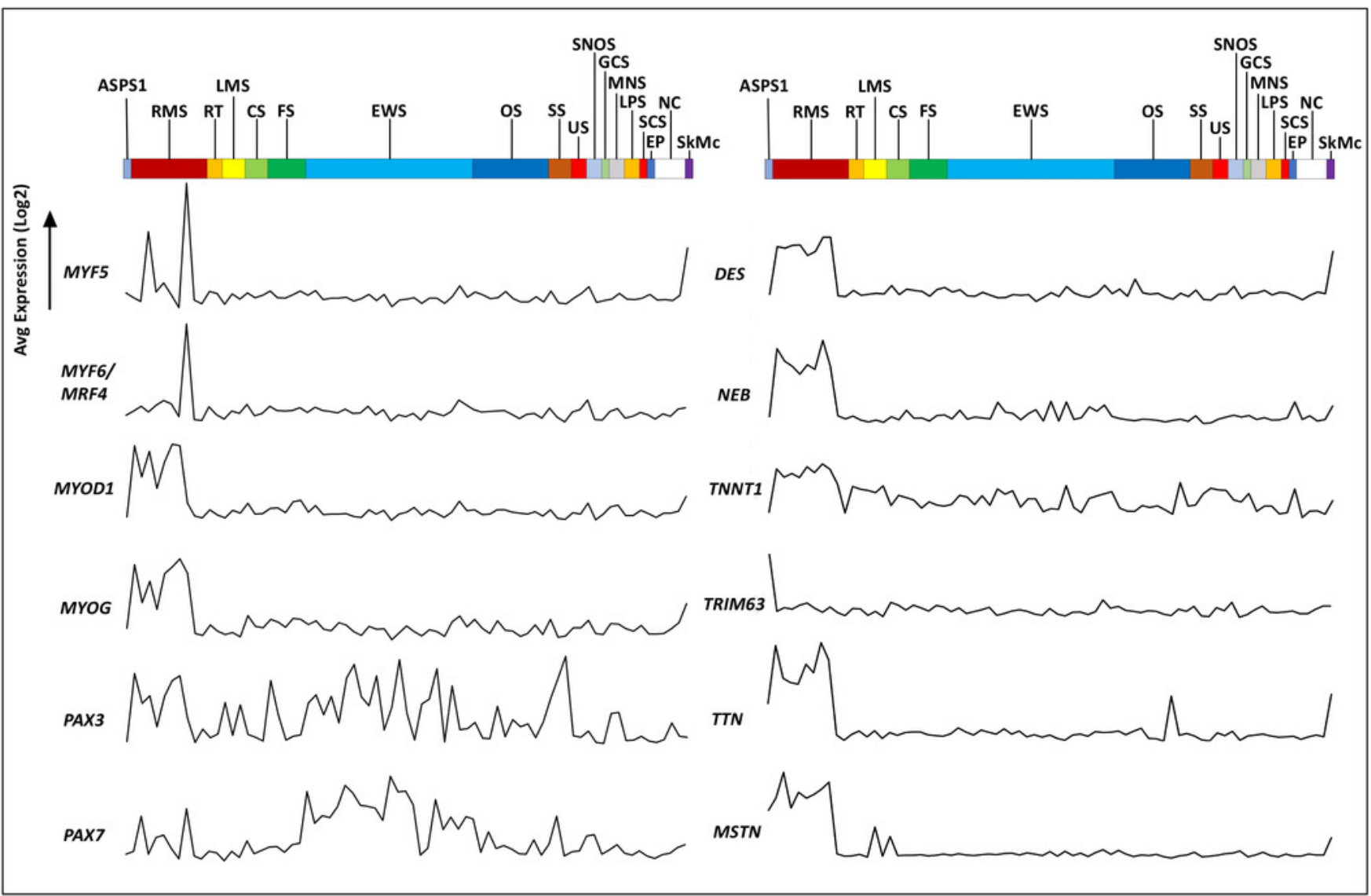


Figure 4

VENN diagram showing overlap between analyses.

Lists of over-expressed transcripts (five-fold cut off) were used to determine extent of overlap between the five datasets. The number of differentially expressed transcripts at fivefold is underlined. Callouts show the 25 transcripts over-expressed in all experiments and the 73 found in all ASPS patient analyses. 


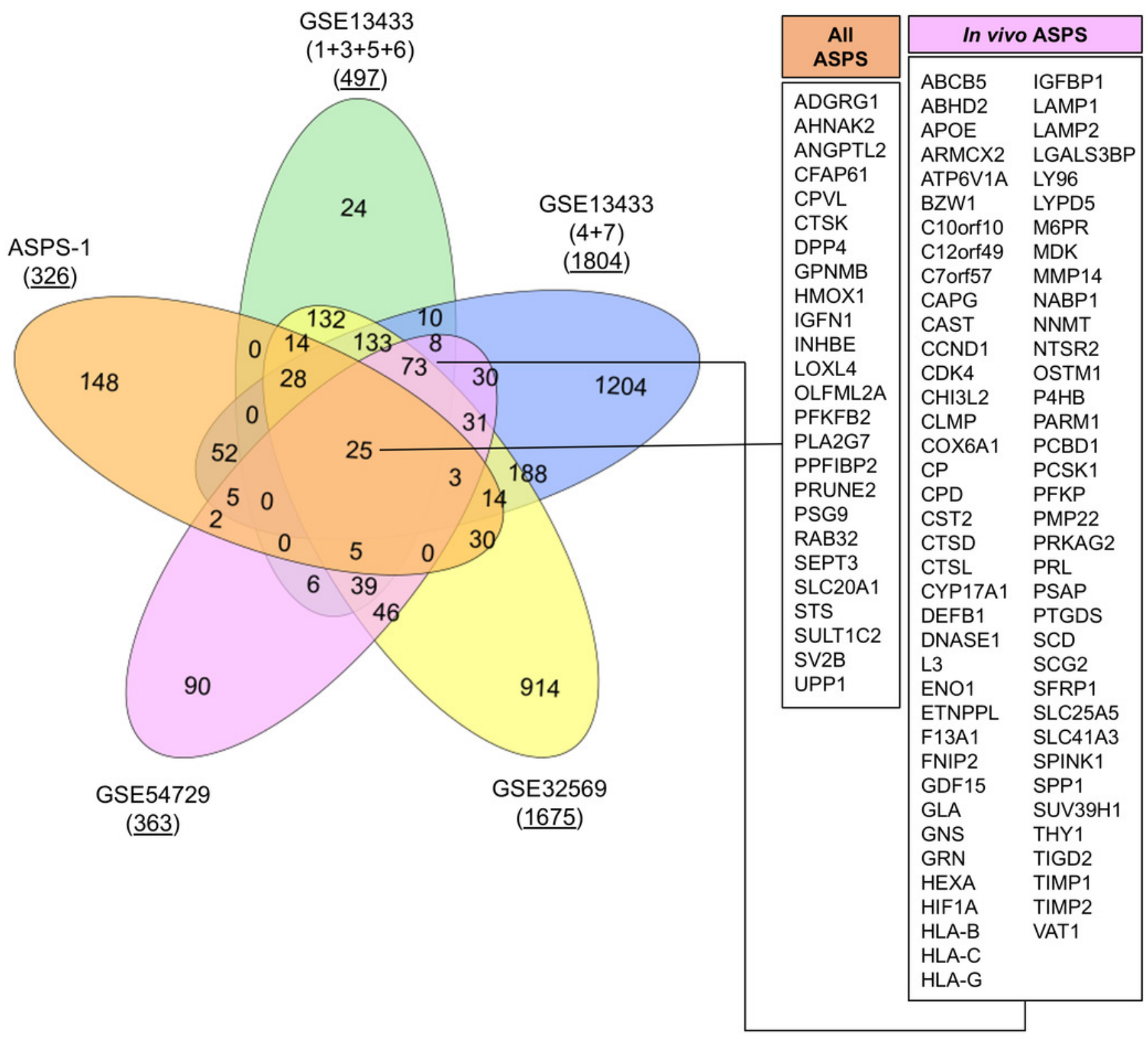




\section{Table $\mathbf{1}$ (on next page)}

The top fifty over-expressed genes in ASPS-1 relative to the average of the $\mathrm{NCl}$ sarcoma cell line panel. 


\begin{tabular}{|c|c|c|c|}
\hline Gene Symbol & Affy ID & Description & FCASPS-1 vs. Av \\
\hline CRYAB; FDXACB1 & 3391149 & crystallin alpha B; ferredoxin-fold anticodon binding domain containing 1 & 227.1 \\
\hline MT1G & 3692999 & metallothionein $1 \mathrm{G}$ & 202.9 \\
\hline C7orf69 & 3000905 & chromosome 7 open reading frame 69 & 202.0 \\
\hline GCSAML & 2390102 & germinal center-associated, signaling and motility-like & 177.6 \\
\hline SV2B & 3608638 & synaptic vesicle glycoprotein $2 \mathrm{~B}$ & 132.6 \\
\hline ADGRL4 & 2419432 & adhesion $\mathrm{G}$ protein-coupled receptor $\mathrm{L} 4$ & 129.9 \\
\hline PLA2G7 & 2955827 & phospholipase A2, group VII & 93.5 \\
\hline SULT1C2 & 2498911 & sulfotransferase family $1 \mathrm{C}$ member 2 & 91.3 \\
\hline SLN & 3389954 & sarcolipin & 88.9 \\
\hline CFAP61 & 3878972 & cilia and flagella associated protein 61 & 85.2 \\
\hline PPEF1 & 3970714 & protein phosphatase, EF-hand calcium binding domain 1 & 82.4 \\
\hline ACP5 & 3851072 & acid phosphatase 5 , tartrate resistant & 79.8 \\
\hline CD36 & 3010503 & CD36 molecule (thrombospondin receptor) & 79.1 \\
\hline PPARGC1A & 2763550 & peroxisome proliferator-activated receptor gamma, coactivator 1 alpha & 78.9 \\
\hline ASB11 & 4000485 & ankyrin repeat and SOCS box containing 11 , E3 ubiquitin protein ligase & 78.1 \\
\hline BMP5 & 2958172 & bone morphogenetic protein 5 & 74.9 \\
\hline PRUNE2 & 3210616 & prune homolog 2 (Drosophila) & 72.3 \\
\hline SUCNR1 & 2648098 & succinate receptor 1 & 66.5 \\
\hline PSG9 & 3864286 & pregnancy specific beta-1-glycoprotein 9 & 66.0 \\
\hline CKMT2 & 2818035 & creatine kinase, mitochondrial 2 (sarcomeric) & 61.7 \\
\hline DPP4 & 2584018 & dipeptidyl-peptidase 4 & 61.2 \\
\hline $\mathrm{ABCB} 1$ & 3060182 & ATP binding cassette subfamily B member 1 & 59.7 \\
\hline $\mathrm{SCIN}$ & 2990404 & scinderin & 58.7 \\
\hline FABP3 & 2404418 & fatty acid binding protein 3 , muscle and heart & 55.8 \\
\hline PRUNE2 & 3210497 & prune homolog 2 (Drosophila) & 55.7 \\
\hline SLC27A2 & 3593575 & solute carrier family 27 (fatty acid transporter), member 2 & 54.7 \\
\hline SLCO4C1 & 2869096 & solute carrier organic anion transporter family, member $4 \mathrm{C} 1$ & 51.9 \\
\hline PSG11,5,4,2 & 3863929 & pregnancy specific beta-1-glycoprotein $11,5,4,2$ & 50.4 \\
\hline PRLR & 2853102 & prolactin receptor & 47.9 \\
\hline NPY6R & 2830450 & neuropeptide Y receptor Y6 (pseudogene) & 44.6 \\
\hline ANXA3 & 2732844 & annexin A3 & 43.2 \\
\hline TRPC7 & 2876793 & transient receptor potential cation channel, subfamily $\mathrm{C}$, member 7 & 42.9 \\
\hline CD5L & 2439138 & CD5 molecule-like & 41.0 \\
\hline AKR1C2 & 3274758 & aldo-keto reductase family 1 , member $\mathrm{C} 2$ & 40.9 \\
\hline GPNMB & 2992814 & glycoprotein (transmembrane) $\mathrm{nmb}$ & 40.3 \\
\hline IL13RA2 & 4018729 & interleukin 13 receptor, alpha 2 & 39.1 \\
\hline LRRC39 & 2425173 & leucine rich repeat containing 39 & 38.8 \\
\hline CST1 & 3901361 & cystatin SN & 37.4 \\
\hline $\mathrm{CDH7}$ & 3792273 & cadherin 7 , type 2 & 36.8 \\
\hline DOK5 & 3889833 & docking protein 5 & 35.1 \\
\hline SEPT3; WBP2NL & 3947227 & septin 3; WBP2 N-terminal like & 34.8 \\
\hline GCNT3 & 3596147 & glucosaminyl ( $\mathrm{N}$-acetyl) transferase 3 , mucin type & 34.8 \\
\hline ENPP5 & 2955673 & ectonucleotide pyrophosphatase/phosphodiesterase 5 (putative) & 34.7 \\
\hline DOK3 & 2888879 & docking protein 3 & 34.2 \\
\hline LCP1 & 3512874 & lymphocyte cytosolic protein 1 (L-plastin) & 34.0 \\
\hline CDA & 2324084 & cytidine deaminase & 33.4 \\
\hline KLHL4 & 3983324 & kelch-like family member 4 & 33.3 \\
\hline CTSK & 2434609 & cathepsin K & 31.5 \\
\hline LIPC & 3595691 & lipase, hepatic & 31.0 \\
\hline RPSA & 3827218 & ribosomal protein SA & 30.0 \\
\hline
\end{tabular}




\section{Table 2 (on next page)}

The top fifty upregulated transcripts generated from each of the four experiments utilizing ASPS patient data from GSE13433, GSE32569 and GSE54729 


\begin{tabular}{|c|c|c|c|c|c|c|c|c|c|c|c|}
\hline \multicolumn{3}{|c|}{$\begin{array}{l}\text { GSE13433 } \\
\text { Patients } 1,3,5,6 \text { vs. Skeletal muscle }\end{array}$} & \multicolumn{3}{|c|}{$\begin{array}{l}\text { GSE13433 } \\
\text { Patient 4,7 vs. Normal lung }\end{array}$} & \multicolumn{3}{|c|}{\begin{tabular}{|l|} 
GSE32569 \\
Pre-treatment ASPS vs. Skeletal muscle
\end{tabular}} & \multicolumn{3}{|c|}{$\begin{array}{l}\text { GSE54729 } \\
\text { Patients vs. Skeletal muscle }\end{array}$} \\
\hline AFFY ID & FC & GENE ID & AFFY ID & FC & GENE ID & AFFY ID & FC & GENE ID & Ensembl ID & FC & Gene ID \\
\hline 205502_at & 639.7 & CYP17A1 & 207733_x_at & 608.6 & PSG9 & 211470_s_at & 573.8 & SULT1C2 & ENSG00000159871 & 100.9 & LYPD5 \\
\hline 212992_at & 531.8 & AHNAK2 & 209594_x_at & 601.3 & PSG9 & 205502_at & 420.6 & CYP17A1 & ENSG00000183979 & 423.1 & NPB \\
\hline 205445_at & 434.1 & PRL & 205445_at & 572.3 & PRL & 1554018_at & 375.0 & GPNMB & ENSG00000198203 & 237.6 & SULT1C2 \\
\hline 240717_at & 419.0 & ABCB5 & 205502_at & 537.1 & CYP17A1 & 205342_s_at & 367.4 & SULT1C2 & ENSG00000148795 & 1700.4 & CYP17A1 \\
\hline 205342_s_at & 338.7 & SULT1C2 & 1555786_s_at & 510.2 & LINC00520 & 210809_s_at & 365.1 & POSTN & ENSG00000146678 & 200.6 & IGFBP1 \\
\hline 201850_at & 258.8 & CAPG & 206224_at & 467.6 & CST1 & 238720_at & 351.1 & LOC101927057 & ENSG00000172179 & 357.1 & PRL \\
\hline 211470_s_at & 252.9 & SULT1C2 & 223572_at & 437.6 & HHATL & 210587_at & 341.2 & INHBE & ENSG00000169006 & 142.2 & NTSR2 \\
\hline 238720_at & 248.1 & LOC101927057 & 240717_at & 346.4 & ABCB5 & 206214_at & 262.4 & PLA2G7 & ENSG00000101197 & 113.9 & BIRC7 \\
\hline 1554018_at & 240.8 & GPNMB & 208555_x_at & 322.5 & CST2 & 212992_at & 259.6 & AHNAK2 & ENSG00000170369 & 345.4 & CST2 \\
\hline 205302_at & 207.6 & IGFBP1 & 236972_at & 277.8 & TRIM63 & 1565162_s_al & 241.7 & MGST1 & ENSG00000100167 & 143.8 & SEPT3 \\
\hline 204638_at & 198.2 & ACP5 & 1553663_a_at & 259.2 & NPB & 229831_at & 228.7 & CNTN3 & ENSG00000204632 & 396.4 & HLA-G \\
\hline 206899_at & 170.8 & NTSR2 & 205302_at & 255.8 & IGFBP1 & 200832_s_at & 225.4 & SCD & ENSG00000146070 & 147.4 & PLA2G7 \\
\hline 210587_at & 170.4 & INHBE & 221051_s_at & 200.5 & NMRK2 & 206899_at & 168.5 & NTSR2 & ENSG00000110492 & 313.0 & MDK \\
\hline 212805_at & 157.6 & PRUNE2 & 206239_s_at & 192.8 & SPINK1 & 205302_at & 159.6 & IGFBP1 & ENSG00000227925 & 134.1 & LOC101929771 \\
\hline 209875_s_at & 150.3 & SPP1 & 210587_at & 184.3 & INHBE & 227180_at & 157.3 & ELOVL7 & ENSG00000170373 & 455.2 & CST1 \\
\hline 1557636_a_at & 145.1 & C7orf57 & 206899_at & 171.9 & NTSR2 & 219648_at & 149.3 & MREG & ENSG00000225328 & 118.5 & LINC01594 \\
\hline 210809_s_at & 144.4 & POSTN & 205551_at & 169.9 & SV2B & 210397_at & 148.0 & DEFB1 & ENSG00000118785 & 260.1 & SPP1 \\
\hline 221577_x_at & 134.0 & GDF15 & 219106_s_at & 149.9 & KLHL41 & 209875_s_at & 147.2 & SPP1 & ENSG00000139269 & 137.6 & INHBE \\
\hline 221008_s_at & 133.2 & ETNPPL & 206799_at & 146.3 & SCGB1D2 & 557636_a_al & 145.3 & C7orf57 & ENSG00000102575 & 190.9 & ACP5 \\
\hline 206214_at & 130.1 & PLA2G7 & 229052_at & 143.1 & ANKRD23 & 205825_at & 139.0 & PCSK1 & ENSG00000185518 & 114.7 & $S V 2 B$ \\
\hline 209035_at & 122.3 & MDK & 221008_s_at & 142.4 & ETNPPL & 219073_s_at & 138.2 & OSBPL10 & ENSG00000205336 & 129.2 & ADGRG1 \\
\hline 202450_s_at & 121.7 & CTSK & 205342_s_at & 125.6 & SULT1C2 & 205343_at & 132.8 & SULT1C2 & ENSG00000185567 & 246.4 & AHNAK2 \\
\hline 200832_s_at & 121.0 & SCD & 212805_at & 124.7 & PRUNE2 & 555778_a_al & 127.5 & POSTN & ENSG00000136235 & 2756.8 & GPNMB \\
\hline 212806_at & 119.7 & PRUNE2 & 1564758_at & 115.7 & LOC643659 & 221008_s_at & 126.1 & ETNPPL & ENSG00000042493 & 172.1 & CAPG \\
\hline 230067_at & 116.8 & FAM124A & 229831_at & 114.5 & CNTN3 & 231736_x_at & 116.1 & MGST1 & ENSG00000143387 & 1718.2 & CTSK \\
\hline 208555_x_at & 116.8 & CST2 & 209738_x_at & 113.4 & PSG6 & 212805_at & 115.1 & PRUNE2 & ENSG00000030582 & 707.5 & GRN \\
\hline 225275_at & 115.8 & EDIL3 & 233389_at & 107.5 & CFAP61 & 558378_a_al & 108.4 & AHNAK2 & ENSG00000107317 & 354.1 & PTGDS \\
\hline 229831_at & 112.1 & CNTN3 & 212992_at & 106.9 & AHNAK2 & 218292_s_at & 98.4 & PRKAG2 & ENSG00000106617 & 161.8 & PRKAG2 \\
\hline 227404_s_at & 111.2 & EGR1 & 233238_s_at & 106.0 & СТВ-12O2.1 & 221577_x_at & 94.6 & GDF15 & ENSG00000216490 & 275.5 & IFI30 \\
\hline 212841_s_at & 109.4 & PPFIBP2 & 1569072_s_at & 102.9 & ABCB5 & 218404_at & 94.0 & SNX10 & ENSG00000183696 & 183.0 & UPP1 \\
\hline 216834_at & 108.8 & RGS1 & 206994_at & 87.9 & CST4 & 233748_x_at & 90.8 & PRKAG2 & ENSG00000110092 & 192.1 & CCND1 \\
\hline 208792_s_at & 106.1 & CLU & 239205_s_at & 84.7 & CR1; CR1L & 224918_x_at & 89.1 & MGST1 & ENSG00000212443 & 410.2 & SNORA53 \\
\hline 223362_s_at & 105.2 & SEPT3. & 217871_s_at & 84.7 & MIF & 212070_at & 86.0 & ADGRG1 & ENSG00000185585 & 105.1 & OLFML2A \\
\hline 208791_at & 92.7 & CLU & 226086_at & 83.8 & SYT13 & 205551_at & 85.1 & SV2B & ENSG00000130203 & 285.1 & APOE \\
\hline 1558846_at & 92.7 & PNLIPRP3 & 213175_s_at & 82.5 & SNRPB & 244444_at & 84.5 & PKD1L2 & ENSG00000111412 & 119.3 & C12orf49 \\
\hline 230746_s_at & 92.3 & N/A & 221523_s_at & 81.9 & RRAGD & 208965_s_at & 83.6 & IFI16 & ENSG00000206503 & 1571.8 & HLA-A \\
\hline 218292_s_at & 89.1 & PRKAG2 & 243167_at & 77.0 & ABCB5 & 208146_s_at & 82.8 & CPVL & ENSG00000106066 & 239.3 & CPVL \\
\hline 1565162_s_at & 88.4 & MGST1 & 206372_at & 74.4 & MYF6 & 226847_at & 82.8 & FST & ENSG00000138131 & 108.9 & LOXL4 \\
\hline 205825_at & 83.7 & PCSK1 & 209875_s_at & 70.5 & SPP1 & 223484_at & 80.3 & C15orf48 & ENSG00000118508 & 104.3 & RAB32 \\
\hline 226372_at & 82.7 & CHST11 & 244444_at & 67.3 & PKD1L2 & 234983_at & 78.9 & C12orf49 & ENSG00000174080 & 454.1 & CTSF \\
\hline 202503_s_at & 82.6 & KIAA0101 & 205862_at & 65.9 & GREB1 & 240717_at & 78.3 & ABCB5 & ENSG00000169116 & 207.1 & PARM1 \\
\hline 205343_at & 82.0 & SULT1C2 & 222379_at & 65.8 & KCNE4 & 229177_at & 78.1 & C16orf89 & ENSG00000120885 & 187.0 & MIR6843 \\
\hline 205551_at & 81.7 & SV2B & 1554371_at & 60.2 & PKD1L2 & 205844_at & 75.8 & VNN1 & ENSG00000214435 & 114.9 & AS3MT \\
\hline 1569072_s_at & 81.5 & ABCB5 & 205825_at & 58.2 & PCSK1 & 238376_at & 75.5 & LOC100505564 & ENSG00000130208 & 134.3 & APOC1 \\
\hline 227180_at & 79.8 & ELOVL7 & 222714_s_at & 55.6 & LACTB2 & 205445_at & 73.0 & PRL & ENSG00000100644 & 335.4 & HIF1A \\
\hline 231736_x_at & 79.5 & MGST1 & 218619_s_at & 54.6 & SUV39H1 & 242340_at & 71.7 & N/A & ENSG00000135047 & 458.4 & CTSL \\
\hline 202037_s_at & 76.5 & SFRP1 & 236523_at & 54.3 & LOC285556 & 204285_s_at & 71.3 & PMAIP1 & ENSG00000144136 & 134.6 & SLC2OA1 \\
\hline 219648_at & 74.5 & MREG & 1557636_a_at & 53.7 & C7orf57 & 204466_s_at & 71.3 & SNCA & ENSG00000101846 & 109.4 & STS \\
\hline 206685_at & 71.8 & HCG4 & 212070_at & 52.9 & ADGRG1 & 203767_s_at & 70.7 & STS & ENSG00000111775 & 242.3 & COX6A1 \\
\hline 210397_at & 71.0 & DEFB1 & 204830_x_at & 52.8 & PSG5 & 222872_x_at & 70.5 & NABP1 & ENSG00000089101 & 164.4 & CFAP61 \\
\hline
\end{tabular}

